\title{
The promise of sustainability for Iowa
}

\author{
Review by Paul Lasley, Iowa State University*
}

Review of Green, Fair, and Prosperous: Paths to a Sustainable Iowa, by Charles F. Connerly. (2020). University of Iowa Press. Available as paperback and eBook; 228 pages. Publisher's book page: https://www.uipress.uiowa.edu/books/9781609387204/greenfair-and-prosperous

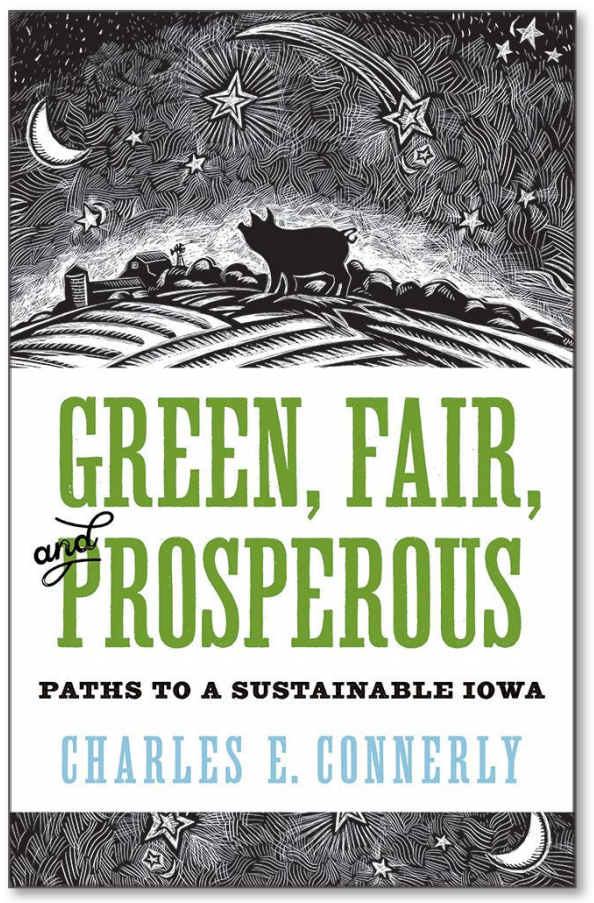

Submitted August 17, 2020 / Published online November 17, 2020

Citation: Lasley, P. (2020). The promise of sustainability for Iowa [Book review]. Journal of Agriculture, Food Systems, and Community Development, 10(1), 285-287. https://doi.org/10.5304/jafscd.2020.101.020

Copyright (C) 2020 by the Author. Published by the Lyson Center for Civic Agriculture and Food Systems. Open access under CC-BY license.

I was first attracted to graduate school in sociology in part to help me understand the nagging question of why some people work hard and yet remain poor. When extrapolated to the community level, I was puzzled by why some communities seem to grow and thrive and yet others decline and stagnate. I wish this book had been available during my graduate training.

\footnotetext{
** Paul Lasley is an Iowa State University professor of sociology, where he has taught several courses, conducted research on rural and agriculture change, and led a nationally recognized Extension program for nearly 40 years. Lasley has been on the cutting edge of documenting many of the changes in Iowa agriculture and rural life for four decades. He can be contacted at Department of Sociology, 312 East Hall, Iowa State University, Ames, IA 50011 USA; +1- 515-294-0937; plasley@iastate.edu
}

Two essential dimensions of community economic development are the natural resource base of the community and the qualities of the workforce, what is often referred to as the human capital of local residents. Jeopardizing either the resource base or failing to invest in people generally diminishes the opportunities for economic development. Likewise, spoil the environment and it becomes less attractive to live in and those who can migrate elsewhere. Failing to invest in education and skill training often results in a marginalized population that cannot fully engage in the growth and development of the community.

This book's underpinning is that sustainable development can be represented as a three-legged stool: economic development, environment protection, and social justice. Each of the legs must be 
the same length for the stool be stable. To achieve long term sustainability, economic development must be held in check by ensuring that everyone benefits, otherwise the resulting drift toward greater inequality will hamper future growth. On the other hand, if environment protection is carried to excess, it will thwart economic development, leading to stagnation. Lack of attention to social justice-ensuring that everyone shares in the abundance of growth and development - will lead to an underclass that will eventually undermine political stability. It is in stagnate economies, mired by high levels of stratification and environmental abuse, where the greatest social disparities exist. Wherever environmental abuse exists, one generally finds high levels of economic and social inequalities.

As a backdrop for the need for sustainable development, Connerly asks the daunting question, "what kind of state does Iowa want to be?" Based on his research and historical analyses, Connerly writes, "Iowans are at the crossroads when it comes to answering this question. Put bluntly, neither the state's environmental nor its social justice record is exemplary, and Iowa appears to be on the path in which environmental degradation is made justifiable by the health of the economy—or at least the agricultural portion of the economy" (p. 20).

Implementing change starts with awareness of and interest in the need for new approaches and acceptance of new ideas. The book provides awareness of the urgency to address the forces restructuring the state and provides an excellent historical review of the trends that have shaped the tall grass prairie states (principally Illinois and Iowa, with some portions of Indiana, Minnesota, Missouri, Kansas, the Dakotas, and Wisconsin). The primary focus is on trends in Iowa, which Connerly uses as a microcosm of the major features of the tall prairie states. While one might quibble with the forces that he identifies or that other forces should have been included, the book presents a historical analysis of how national and state policies have shaped the economy and culture of the state and suggests that unless new directions are taken, these historical forces will limit the prospects for the future.

Chapter one provides historical analysis of the dominant forces that were responsible for the set- tlement of the tall grass prairie states, including discussions of the role of transportation (especially the railroads), slaughter plants, and manufacturing of farm equipment, and how these forces coalesce around growing dependency on major urban areas. Through markets, the processing and distribution of farm outputs, and the acquisition of purchased inputs, the economy of Iowa is closely tied to the major Midwest cities of Chicago, Minneapolis, St. Louis, and Kansas City.

Chapter two opens with a discussion of the great expansion of establishing farms and breaking of the prairies (1860-1900). In 1860, only about 2.7 million acres (about 7\%) of Iowa's total land was devoted to farming; however, 40 years later, 34.6 million acres, or about $96 \%$ of the land in the state, were being farmed. This pioneering settlement era was extended through improved farm equipment and the engineering of drainage systems, along with discoveries of improved plant and animal genetics and commercial fertilizers, culminating in an industrial approach to farming. Sadly, the emphasis on increased production and efficiencies has not always translated into farm profits or robust rural communities, as evidenced by the farm crisis during the 1980s. More recently, this contradiction has been illuminated by the fact that 67 of Iowa's 99 counties lost population between 2000 and 2017, and nearly two-thirds of Iowa's communities lost population.

Chapter three presents the numerous challenges facing Iowa agriculture, with considerable attention paid to the environmental and climatic changes underway. Exploring Iowa's contribution to the hypoxia problem, or what is commonly referred to as the Dead Zone in the Gulf of Mexico, the difficulties presented by challenging the authority to regulate point-source pollution from agricultural drainage districts, and the creation of the Iowa Nutrient Reduction Strategy illustrate growing awareness among many in the state that new approaches to environmental stewardship are needed.

Chapter four provides an understanding to the question, "why is Iowa so white?" Iowa is the nation's sixth "whitest" state, and even though the state boasts of progressive court decisions on race relations, there are other policy actions designed to 
discourage African American settlement in the state. Reflecting on the historical treatment of Native Americans, African Americans, Hispanics, and Asian Americans, Connerly challenges the complicity of the dominant white populations in not doing more to welcome diversity throughout the state.

Chapter five provides a set of twelve general principles and recommendations to achieve sustainability by addressing economic development, environmental protection, and social justice. Each of the principles identified by Connerly is "doable" and would likely position the state for a more sustainable future, but they are still lacking the impetus to motivate state and community leaders to consider these new challenges as opportunities.

It is my opinion that the book would have been strengthened by more attention to the role of leadership in motivating Iowans to consider the challenges the author identifies. Many of the actions that Connerly suggests will require group action through strong local and state leadership. The book provides a greater understanding of the forces that have shaped the state and region. The first step in bringing about social change is recognition of the issue and a willingness to explore new approaches. This book contributes to a better understanding of the historical forces that have shaped Iowa and the need for new approaches to its long-term challenges.

In reading the book, I kept recalling the three questions posed by C. Wright Mills in The Sociological Imagination (1959):

1. What is the present structure of society and how does it differ from previous ones?

2. What are the dominant forces responsible for these changes?

3. What are the consequences of these changes?

As a sociologist, I appreciate Connerly's historical analysis and how this book is implicitly guided by a social-historical analysis. The book would be excellent required reading for an upper-level undergraduate or graduate course in the social and environmental sciences, as well as in community and regional planning. It would be a valuable addition to the library of those interested in understanding the challenges of midwestern states. I highly recommend it.

\section{Reference}

Mills, C. W. (1959). The sociological imagination. Oxford: Oxford University Press. 